\title{
Molecular epidemiology of Streptococcus uberis intramammary infections: Persistent and transient patterns of infection in a dairy herd
}

\author{
K. Leelahapongsathon, ${ }^{1} \odot$ Y. H. Schukken, ${ }^{2,3} \odot$ A. Srithanasuwan, ${ }^{4} \odot$ and W. Suriyasathaporn ${ }^{4 *} \oplus$ \\ ${ }^{1}$ Department of Veterinary Public Health, Faculty of Veterinary Medicine, Kasetsart University, Nakhon Pathom, 73140 Thailand \\ ${ }^{2} \mathrm{GD}$ Animal Health, PO Box 9, 7400 AA Deventer, the Netherlands \\ ${ }^{3}$ Department of Animal Sciences, Wageningen University, PO 9101, 6700 HB, Wageningen, the Netherlands \\ ${ }^{4}$ Research Center of Producing and Development of Products and Innovations for Animal Health and Production, Faculty of Veterinary Medicine, \\ Chiang Mai University, Chiang Mai, 50100 Thailand
}

\section{ABSTRACT}

A longitudinal observational study was carried out to explore transmission dynamics and duration of infection of Streptococcus uberis. Quarter milk samples were collected aseptically for bacterial culture from all lactating cows once a month over a 10 -mo period. Molecular typing of S. uberis mastitis was performed using pulsed-field gel electrophoresis (PFGE). Molecular typing was used to determine episodes of $S$. uberis intramammary infection (IMI). Comparisons of spontaneous cure among PFGE types were performed using Fisher's exact chi-squared tests. Differences of duration among PFGE types and between periods of lactation were tested with Kaplan-Meier survival curves and Cox's proportional hazard model. Among a total of 851 quarter samples, 145 milk samples were detected with $S$. uberis presence. Based on results of PFGE, 66 episodes of $S$. uberis IMI were determined. From the 8 main PFGE types (A-H), PFGE type D, E, F1, F2, G, and $\mathrm{H}$ had only one episode indicating no evidence for transmission, subsequently defined as environmental S. uberis strains. In contrast, PFGE types A1, A2, B, $\mathrm{C} 1$, and $\mathrm{C} 2$ had at least 2 infection episodes caused by the same strain in different quarters or cows, indicating that these strains would be able to transmit to other quarters or cows. These strains were defined as contagious strains. The majority of IMI were attributable to PFGE type A1 (55\%), B (17\%), and A2 (11\%). Spontaneous cures were observed in 35 IMI episodes. Of these 35 IMI cures, $91.4 \%$ were in IMI with duration of infection of $1 \mathrm{mo}, \mathrm{n}=25$, and $2 \mathrm{mo}, \mathrm{n}=6$. The remaining $8.6 \%$ was in IMI with duration of infection $>2 \mathrm{mo}, \mathrm{n}=4$. Based on results from Cox's proportional hazard model, environmental $S$. uberis episodes were likely to have spontaneous cure with shorter duration

Received July 17, 2019.

Accepted December 9, 2019.

*Corresponding author: suriyasathaporn@hotmail.com compared with contagious S. uberis with PFGE type B (hazard ratio $=8.4$ ). Quarters infected with S. uberis strain PFGE type A in early lactation were more likely to persist compared with those infected in late lactation (hazard ratio $=7.57$ ). In conclusion, the majority of $S$. uberis IMI in this herd were transient and showed spontaneous cure. In addition to environmental S. uberis IMI, at least 3 types of contagious IMI $S$. uberis can be defined as (1) short duration of IMI and likely to have spontaneous cure, (2) long duration and unlikely to have spontaneous cure, and (3) wide range of duration of IMI either transient or persistent where spontaneous cure may occur depending on host defense capacity.

Key words: Streptococcus uberis, duration of infection, spontaneous cure, persistent mastitis

\section{INTRODUCTION}

As with most infectious diseases, mastitis incidence depends on 3 components: virulence and quantity of invading microbes, udder defense efficiency, and environmental risk factors. After bacterial invasion, an acute phase of udder defense mechanism attempts to resolve IMI immediately (Suriyasathaporn et al., 2000a). For udder defense mechanism, results of these attempts can be separated into either successful, as bacteriological spontaneous cure, or unsuccessful eliminations. In the case of spontaneous cure, the bacteria are completely destroyed, recruitment of neutrophil from the acute phase ceases, and a transient IMI occurs. In the case of unsuccessful elimination, the IMI may proceed in 2 ways. The first would be an IMI with an aggressive immune response causing clinical mastitis. The second option would be an IMI resulting in a less aggressive immune response, resulting in persistence of the IMI without clinical signs (Ezzat Alnakip et al., 2014). Factors relating to unsuccessful elimination include bacterial species, amount of pathogens, and host defense efficiency. For example, S. agalactiae, a contagious mas- 
titis pathogen, showed a very low spontaneous cure rate and long duration of IMI (Leelahapongsathon et al., 2016). A low mammary immune response capability, indicated by very low pre-infection SCC, was associated with a higher risk of subsequent clinical mastitis (Suriyasathaporn et al., 2000b). In subclinical mastitis, the duration of IMI ranged from a few weeks to $1 \mathrm{yr}$ (Supré et al., 2011). Duration of IMI for a period longer than 2 mo is generally defined as persistent (ThompsonCrispi et al., 2014).

Streptococcus uberis has been defined as either an environmental or a contagious intramammary pathogen in dairy cattle. In several studies, profiles of $S$. uberis isolated from intramammary infected quarters had a high degree of genetic heterogeneity among isolates, suggesting that most cases of S. uberis are not contagious and likely arise from the cows' environment (Khan et al., 2003; McDougall et al., 2004; Abureema et al., 2014). Data from clinical mastitis studies showed that second and subsequent episodes of S. uberis clinical mastitis are commonly caused by new strains, likely also acquired from the cow's environment (Abureema et al., 2014). However, an outbreak of $S$. uberis mastitis has also been described as the likely result of contagious transmission (Zadoks et al., 2001, 2003; Leelahapongsathon et al., 2016). In these studies, the use of molecular typing methods to discriminate strains of S. uberis identified identical strains among multiple quarters and cows in the herd. Such a clonal outbreak likely indicates cow-to-cow transmission of $S$. uberis (Zadoks et al., 2003; Pullinger et al., 2007; Rato et al., 2008). Pulsed-field gel electrophoresis (PFGE) is a highly discriminative molecular typing technique that is used in epidemiological studies worldwide.

Several studies showed that IMI from S. uberis, regardless of their transmission characteristics, can be both transient and persistent with an infection duration ranging from 1 to $370 \mathrm{~d}$ (Todhunter et al., 1995; Pullinger et al., 2007; Leelahapongsathon et al., 2016). It might be hypothesized that differences in IMI duration may be either attributable to the specific strain of $S$. uberis or to the udder defense mechanisms of the host. Based on the above quoted literature, our hypothesis was that $S$. uberis strains might be separated into 3 types. These 3 types were (1) environmental with a transient IMI, fast spontaneous cure without transmission, (2) contagious with a transient IMI, spontaneous cure with evidence of transmission, and (3) contagious with persistent IMI, no cure, and evidence of transmission. In addition, the stage of lactation at IMI was evaluated as a possible cow factor related to the efficacy of the udder defense in eliminating IMI S. uberis. Therefore, the purpose of this study was to investigate transmission and duration characteristics of $S$. uberis
IMI and the association of IMI transmission and duration with molecular strain type of $S$. uberis.

\section{MATERIALS AND METHODS}

\section{Herd and Animals}

The study was conducted in a small holder dairy herd in the Pha-tung dairy cooperative, Chiang Mai, Thailand. Before the start of the longitudinal study, in November 2012, the farmer contacted the dairy extension team, Faculty of Veterinary Medicine, Chiang Mai University, for a herd mastitis investigation because of a very high bulk milk SCC $(>1,000,000$ cells $/ \mathrm{mL})$. In this investigation, all quarter milk samples were tested for the presence of either subclinical mastitis, defining by California mastitis test score $\geq 2$, or clinical mastitis. All affected quarters were sampled aseptically for subsequent bacteriological culture. From a total of 104 quarters from 27 cows, 49 (47.1\%) quarter milk samples from 18 cows $(66.7 \%)$ were submitted for bacteriological culture. In these 49 samples, we identified CNS ( $\mathrm{n}=$ $7)$, other streptococci $(\mathrm{n}=4)$, and $S$. uberis $(\mathrm{n}=10)$ in the 21 culture-positive samples. We therefore concluded that $S$. uberis IMI was the dominant problem in this herd.

Thereafter, with the permission of the farmer, a 10mo longitudinal study was undertaken during January to October 2013 to investigate the epidemiology of $S$. uberis IMI in this herd. Collection of quarter milk samples of all milking cows once a month was performed regardless of their subclinical or clinical mastitis status. During the study, 8 cows were culled $(3,1,3$, and 1 cow in May, July, September, and October, respectively) and 4 new cows were introduced to the herd (3 cows in May, and 1 cow in July). Antibiotic treatment was decided, practiced, and documented by the farmer when clinical mastitis, an obvious abnormality of the udder, or secretion occurred.

The herd was housed in tiestall facilities with a concrete floor and consisted of approximately 27 crossbred Holstein Friesian lactating cows, with an average daily milk production of $6.5 \mathrm{~kg} / \mathrm{cow}$ per day. Cows were milked twice daily with 2 sets of bucket-type milking instruments on a set of vacuum pumps. Relative poor husbandry and milking practices without regular maintenance of the milking machines were observed in this herd. For example, use of individual paper towels, immediate postmilking teat disinfection, segregating infected cows, milking known infected cows last, blanket dry cow therapy, and routine culling of cows with persistent IMI or recurrent clinical mastitis were not practiced. The farmer's decision on antibiotic treatment of clinical cases of mastitis was based on the severity 
of clinical mastitis and the number of mastitis quarters within the affected cow.

\section{Milk Sample Collection and Bacteriologic Analysis}

Quarter milk samples were collected at monthly intervals (from January to October 2013) from all lactating cows using aseptic technique. Data on clinical mastitis, antibiotic treatment and dates of calving, dryoff, or culling were recorded. Milk samples were stored on ice at 4 to $8^{\circ} \mathrm{C}$ and arrived in the laboratory within 2 to $4 \mathrm{~h}$ from collection. Bacterial species were identified according to National Mastitis Council standards (Harmon et al., 1990). Briefly, $10 \mu \mathrm{L}(0.01 \mathrm{~mL})$ of milk were applied onto one quarter of a $5 \%$ blood agar plate and incubated for up to $48 \mathrm{~h}$ at $37^{\circ} \mathrm{C}$. Preliminary identification of $S$. uberis was based on colony morphology and esculin hydrolysis on Edward's medium. The final identification of $S$. uberis isolates was based on colony morphology, and biochemical tests (hemolysis pattern, catalase reaction, esculin reaction, inulin fermentation, mannitol fermentation, salicin fermentation, and sodium hippurate reaction). The number of colony-forming units was recorded. Isolates were confirmed as S. uberis by PCR amplification of species-specific parts of the $16 \mathrm{~S}$ rRNA gene, and the 23S rRNA gene (Hassan et al., 2001).

\section{Definition of Infection and Episode of Infection}

A quarter was defined as being infected with $S$. uberis when $\geq 1,000 \mathrm{cfu} / \mathrm{mL}$ of a pathogen was cultured from a single sample, when $\geq 500 \mathrm{cfu} / \mathrm{mL}$ was cultured from 2 of 3 consecutive milk samples, when $\geq 100 \mathrm{cfu} /$ $\mathrm{mL}$ was cultured from 3 consecutive milk samples, or when $\geq 100 \mathrm{cfu} / \mathrm{mL}$ was cultured from a sample of a clinical case according to previously published IMI definitions (Zadoks et al., 2003). Samples containing more than 3 bacterial species were considered contaminated and were not informative of IMI status. A previously infected quarter was considered recovered from IMI if none of the above definitions were applicable and the sample was free of $S$. uberis. Quarters that recovered from IMI were eligible for a new episode of infection. Based on the suggestion of Abureema et al. (2014), the same or closely related PFGE types isolated from the same quarter within a period of 8 wk was defined as persistent infection.

After 10 mo of sample collection and subsequent bacteriological culture, all isolates of $S$. uberis were arranged at quarter level based on date of sample collection. An episode of infection, a group of consecutive isolates of $S$. uberis from the same quarter and within the same lactation was first evaluated by species con- firmation PCR. The final determination of an S. uberis episode was then confirmed by the presence of the same PFGE type. For PFGE analysis, with an episode of infection with less than or equal to 3 isolates, all isolates were taken, and only the first, middle, and last isolates were taken from an episode with more than 3 isolates. Subsequently, PFGE types were then used to determine the $S$. uberis IMI episodes.

\section{PFGE Analysis}

DNA Extraction. Streptococcus uberis isolates were grown on $5 \%$ bovine blood agar overnight at $37^{\circ} \mathrm{C}$ and were suspended into $3 \mathrm{~mL}$ of brain-heart infusion broth. The optical density of the broth was measured and adjusted to 1.3 at $600 \mathrm{~nm}$. An $800-\mu \mathrm{L}$ aliquot of cells was pelleted by centrifugation at $18,000 \times g$ for $5 \mathrm{~min}$ at room temperature. Cells were suspended in $240 \mu \mathrm{L}$ of cell suspension buffer (10 $\mathrm{m} M$ Tris, $\mathrm{pH} 7.2 ; 20 \mathrm{mM}$ $\mathrm{NaCl}, 50 \mathrm{~m} M$ EDTA) and $60 \mu \mathrm{L}$ of freshly prepared 10 $\mathrm{mg} / \mathrm{mL}$ lysozyme were added. The suspension was incubated at $37^{\circ} \mathrm{C}$ for $10 \mathrm{~min}$. The bacterial suspension was mixed with $300 \mu \mathrm{L}$ of $1 \%$ chromosomal grade agarose (1 $\mathrm{g}$ of chromosomal grade agarose/100 mL of agarose buffer; $10 \mathrm{mg}$ of agarose/1 $\mathrm{mL}$ of agarose buffer) and was dispensed into plug molds. After being solidified, the plugs were incubated at $37^{\circ} \mathrm{C}$ for $1 \mathrm{~h}$ in $500 \mu \mathrm{L}$ of lysis buffer $(10 \mathrm{~m} M$ Tris, $\mathrm{pH}$ 7.2; $50 \mathrm{~m} M \mathrm{NaCl}, 50 \mathrm{~m} M$ EDTA, $0.2 \%$ deoxycholate, $0.5 \%$ Sarkosyl). The plugs were transferred into $500 \mu \mathrm{L}$ of PK-PK buffer $(250 \mathrm{mM}$ EDTA, pH 9; $1 \%$ Sarkosyl, proteinase K $50 \mu \mathrm{g} / 1 \mathrm{~mL}$ of PK Buffer) and were incubated for $2 \mathrm{~h}$ at $50^{\circ} \mathrm{C}$. Following lysis, the plugs were washed 4 times for $30 \mathrm{~min}$ each time with $1.4 \mathrm{~mL}$ of wash buffer $(10 \mathrm{~m} M$ Tris, $\mathrm{pH}$ 7.6; $0.1 \mathrm{~m} M$ EDTA). Plugs were stored at $4^{\circ} \mathrm{C}$ in 1.4 $\mathrm{mL}$ of wash buffer $[10 \mathrm{mM}$ Tris- $\mathrm{HCl}(\mathrm{pH} 7.6)$ and 0.1 m $M$ EDTA; Sigma-Aldrich, St. Louis, MO] until used.

Restriction Endonuclease Digestion. A 2-mm slice of each plug was equilibrated in $100 \mu \mathrm{L}$ of $1 \times$ restriction endonuclease buffer for $30 \mathrm{~min}$ at $25^{\circ} \mathrm{C}$. The restriction buffer was removed and replaced with 100 $\mu \mathrm{L}$ of fresh $1 \times$ restriction endonuclease buffer containing $10 \mathrm{U}$ of $\mathrm{SmaI}$ (New England Biolabs, Ipswich, MA) at $25^{\circ} \mathrm{C}$ overnight.

$\boldsymbol{P F G E}$. The DNA fragments were separated by clamped homogeneous electric field (CHEF) electrophoresis using the CHEF-DRIII system (Bio-Rad Laboratories, Hercules, CA). Plug slices were loaded and electrophoresed in a 1\% PFGE agarose gel in $2 \mathrm{~L}$ of $0.5 \times$ TBE buffer $(0.89 M$ Tris-HCl, $0.89 M$ boric acid, $0.02 \mathrm{M}$ EDTA) at $14^{\circ} \mathrm{C}$. The gel was run at $6 \mathrm{~V} /$ $\mathrm{cm}$ for $20 \mathrm{~h}$ with an initial pulse time of $5.3 \mathrm{~s}$ and a final pulse time of $34.9 \mathrm{~s}$. After electrophoresis, gels were stained in $400 \mathrm{~mL}$ of distilled water with $40 \mu \mathrm{L}$ of 
ethidium bromide $(10 \mathrm{mg} / \mathrm{mL})$ for $30 \mathrm{~min}$ and followed by two 15 -min washes with $500 \mathrm{~mL}$ of distilled water. The lambda molecular weight marker (New England Biolabs) was used as reference pattern to normalize all gels.

Analysis of PFGE Patterns. All PFGE profiles or patterns were analyzed visually and by computer-assisted cluster analysis using the software BioNumerics v. 7.0 (Applied Maths, Sint-Martens-Latem, Belgium). The genetic relationships between fingerprints were calculated by using Dice coefficient, and the unweighted pair group method using arithmetic averages was used to construct a dendrogram with a band position, $2 \%$ tolerance and $2 \%$ optimization parameters. Interpretation of chromosomal DNA restriction pattern was based on the criteria of Tenover et al. (1995). Patterns with more than 3 band differences (with levels of similarity of less than $80 \%$ ) were not considered related and were classified as different PFGE types. Patterns that differed by 1 to 3 bands and had a similarity index of more than $80 \%$ were considered related and were defined as subtypes of a PFGE type. The PFGE patterns with no observed band differences (corresponding to a level of similarity of more than $80 \%$ ) were considered indistinguishable and were interpreted as the same subtype of the same PFGE type. All PFGE types were assigned with capital letters, and subtypes were identified by a numeral suffix. Presence of the same subtype of the same PFGE type occurring in at least 2 different quarters was used to define the strain with this PFGE type as contagious. When a PFGE types occurred in only one quarter, the strain with this PFGE type was defined as environmental.

\section{Statistical Analysis}

Spontaneous cure of an IMI episode was defined when a known infected quarter did not show a positive bacterial culture for at least 2 immediate subsequent samplings. The episodes of infection were defined as either transient or persistent according to Pullinger et al. (2007) with slight modifications. A transient episode was an IMI with identical PFGE isolates for up to 2 consecutive samplings ( 1 or $2 \mathrm{mo}$ ). Isolates of a single PFGE type that persisted in at least 3 consecutive monthly sampling were defined as a persistent IMI episode. Stages of lactation were defined as early and late lactation when the infection episodes started at $<120$ or $\geq 120$ d of lactation, respectively. Statistical analysis was conducted using SAS student edition (SAS Institute Inc., Cary, NC). Comparisons of durations between episodes with and without spontaneous cures for each PFGE type were performed using Student's $t$-test. The duration of IMI from S. uberis of a specific
PFGE type was estimated using Kaplan-Meier survival analysis. For this analysis, the episode with spontaneous cure was defined as failed (= cured), and the episode without spontaneous cures during study was defined as a censored episode. In this study, survival times were defined in 2 ways, as (1) time to spontaneous cure for the cured cases and (2) time to end of follow-up due to either end of study, culling or drying-off, for censored cases. Statistical comparisons of survival strata (e.g., early vs. late lactation) were performed by Cox's proportional hazard model. Statistical significance was declared at $P<0.05$ for all statistical analyses.

\section{RESULTS}

A total of 851 quarter samples were taken from 31 cows during the study period, this included the 4 new cows and 8 culled cows. During the study, 14 cows were dried off with the duration of the dry period ranging from 1 to 5 mo. During the study period, antibiotic treatment was administered to 4 clinical mastitis quarters from one cow at the same point in time. The numbers of quarters per sampling ranged from 96 to 104 during January to June and decreased to 62 to 76 during July to October. One hundred forty-five milk samples from 47 quarters and 19 cows were detected with $S$. uberis as the IMI pathogen. The prevalence of S. uberis IMI at the start of the study was $33.3 \%$ (9 out of 27 ) and $12.5 \%$ (13 out of 104) at cow and quarter level, respectively.

\section{PFGE Typing and Episodes of S. uberis Infection}

Based on bacterial identification confirmed with PCR amplification, 64 episodes of $S$. uberis were determined with a duration from 1 to 10 mo. In total, 112 isolates of $S$. uberis were selected from all IMI episodes for PFGE typing. Patterns obtained by PFGE of chromosomal DNA digested with $S m a$ I yielded 9 to 12 fragments. The PFGE pattern from all isolates of the first sampling in the study is shown in Figure 1. This distribution included 4 different PFGE patterns: A1, $\mathrm{A} 2$, E, and F1. The PFGE types A1 and A2 were the most frequent $S$. uberis types isolated $(\mathrm{n}=11$ for both $\mathrm{A} 1$ and A2).

The dendrogram constructed from all PFGE typesubtypes with cow identification, quarter identification, and month of milk sampling is presented in Figure 2. Genetic heterogeneity among S. uberis isolates recovered from milk was observed. Isolates were separated into 8 PFGE types $(\mathrm{A}-\mathrm{H})$ and subtypes were observed in PFGE type A (subtypes A1, A2), C (subtypes C1, $\mathrm{C} 2$ ), and F (subtypes F1, F2) as determined by SmaI yield with levels of similarity of more than $80 \%$. The 


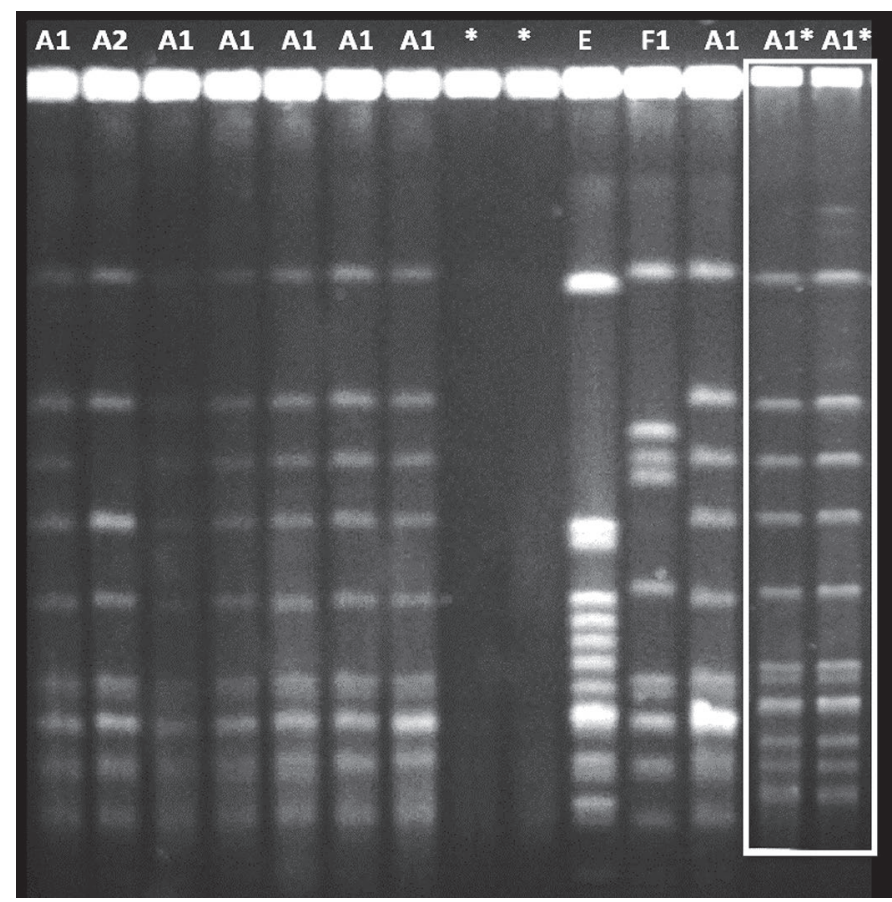

Figure 1. Pulsed-field gel electrophoresis (PFGE) profiles of SmaI macrorestriction fragments of Streptococcus uberis from subclinical mastitis milk quarters isolated from the first sampling of study. Lanes 1 to 14: PFGE types are identified with a capital letter, and subtypes with a numerical suffix for 12 isolates, with * in lanes 13 and 14 indicating the rerun PFGE profiles from isolates in lanes 8 and 9.

visually identified PFGE type A1 $(\mathrm{n}=64)$ was found most frequently, and PFGE type $\mathrm{G}$ and $\mathrm{H}$ were each determined from only 1 isolate. Based on numbers of isolates, PFGE type $\mathrm{B}(\mathrm{n}=20)$ and 2 subtypes of type A (A1, n = 64; A2, $\mathrm{n}=12)$ accounted for $85.7 \%$ $(96 / 112)$ of IMI $S$. uberis in this herd. This showed that the majority of IMI from $S$. uberis in this herd were clonal.

Based on results of PFGE patterns, 66 episodes of S. uberis infection were identified with their cow identification, quarter, and month of milk samples (Figure 3). This was 2 IMI episodes more than those identified using PCR confirmation. Six episodes from cows 3, 5, $11(\mathrm{n}=2), 16$, and 19 were added due to different PFGE type/subtypes among the first, middle, and last isolates of an IMI episode. In contrast, 4 IMI episodes were not different from their previous episodes because of finding the same PFGE subtypes. This occurred after drying-off in cow 4 (right front and left rear) and after treatment with antibiotics in cow 8 (left front and left rear). The majority of IMI episodes of $S$. uberis were attributable to PFGE sub-type A1 (36/66, 55\%), B $(11 / 66,17 \%)$, and A2 $(7 / 66,11 \%)$. From the total of 47 infected quarters, 29 (61.7\%), 14 (29.8\%), and 4 (8.5\%) quarters had 1, 2, and 3 episodes of S. uberis infection during the study, respectively. In 29 quarters with only one episode of infection during the entire study period, most quarters were infected with PFGE sub-type A1 (16/29, 55\%; 10 cows). In 14 quarters with recurrent episodes of infection, most recurrent episodes of infection were recurrent with different PFGE type/ subtype from the original episode ( 8 quarters, 8 cows). Recurrent episodes with same PFGE type were detected in 6 quarters (5 cows). In 4 quarters with 2 recurrent episodes of infection, 2 quarters (cow 5 and cow 11) had second and third recurrent episodes of infection with different PFGE type/subtype from the original episode. For the 2 remaining quarters (cow 8 and cow 11 ), the third recurrent episodes of infection were recurrent with different PFGE type from the initial and the second episodes. PFGE type D, E, F1, F2, G, and H in episodes $3,48,58,64,47$, and 24, respectively, had only one episode indicating no evidence of transmission, and subsequently defined as environmental $S$. uberis strains. In contrast, PFGE type/sub-type A1, A2, B, and C had at least one pair of IMI episodes caused by the same strain in different quarters or cows, indicating that they could transmit to the other quarters or cows. The types were defined as contagious S. uberis strains.

\section{Interval of Episodes}

Infection duration for each $S$. uberis IMI episode is shown in Figure 3. From 66 episodes, 47\% ( $\mathrm{n}=31)$, including PFGE sub-type A1 at $36 \%(13 / 36)$, A2 at $57 \%(4 / 7), \mathrm{B}$ at $91 \%(10 / 11), \mathrm{C} 1$ at $50 \%(2 / 4), \mathrm{F} 2$ at $100 \%(1 / 1)$, and $\mathrm{H}$ at $100 \%(1 / 1)$, were defined as right-censored cases because they lasted until culling or drying-off. Spontaneous cures were observed in 35 episodes including $91.4 \%(32 / 35)$ of transient IMI with duration of infection not more than 2 mo. This include a duration of 1 mo in 25 episodes with A1 $(\mathrm{n}=16), \mathrm{A} 2$ $(\mathrm{n}=3), \mathrm{B}(\mathrm{n}=1), \mathrm{C} 1(\mathrm{n}=2), \mathrm{C} 2(\mathrm{n}=2), \mathrm{F} 1(\mathrm{n}=$ $1)$, and $\mathrm{G}(\mathrm{n}=1)$, and a duration of 2 mo in 6 episodes with A1 $(\mathrm{n}=4), \mathrm{D}(\mathrm{n}=1)$, and $\mathrm{E}(\mathrm{n}=1)$. A persistent IMI $(3 / 35,8.6 \%)$ with a spontaneous cure $>2$ mo was present in 3 IMI episodes, all with type A1. Regardless of their censoring, 12 episodes had a duration of more than 2 mo and subsequently were determined as persistent episodes including episodes with PFGE types A1, A2, and B. These persistent IMI episodes were identified in cow $1,4,5,8$, and 11 . Only persistent episodes from PFGE types A1 with duration less than 6 mo showed spontaneous cure. In contrast, PFGE type/ subtype $\mathrm{C} 1, \mathrm{C} 2, \mathrm{D}, \mathrm{E}, \mathrm{F} 1, \mathrm{~F} 2, \mathrm{G}$, and $\mathrm{H}$ were found to have only transient IMI episodes (1- to 2-mo interval). Among these transient IMI, only IMI with PFGE type $\mathrm{C}$ had more than 1 episode, indicating that this strain potentially transmitted to another quarter. 

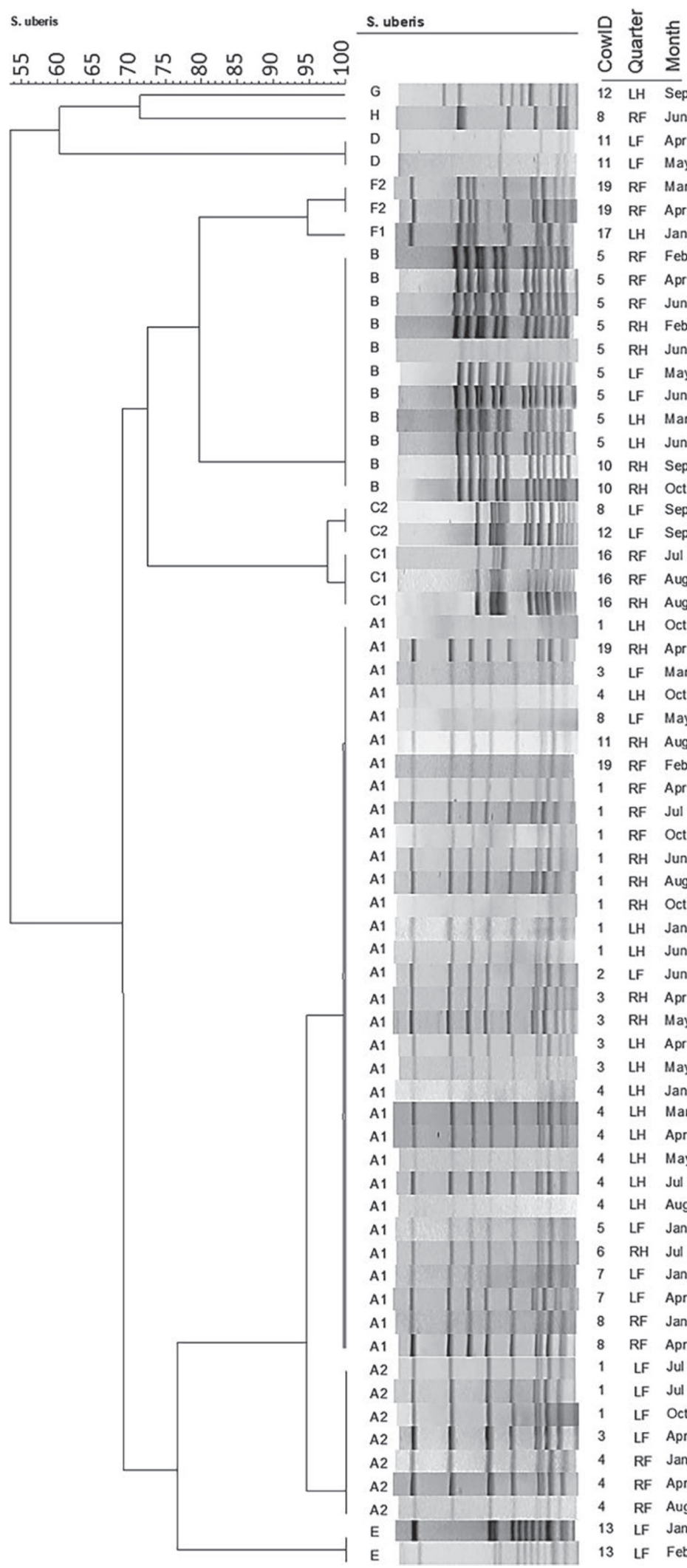

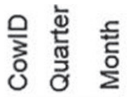

$\begin{array}{lll}12 & \text { LH } & \text { Sep } \\ 8 & \text { RF } & \text { Ju }\end{array}$

11 LF Apr

11 LF May

19 RF Mar

19 RF Apr

17 LH Jan

5 RF Feb

5 RF Apr

5 RF Jun

5 RH Feb

5 RH Jun

5 LF May

5 LF Jun

5 LH Mar

5 LH Jun

$10 \mathrm{RH}$ Sep

$10 \mathrm{RH} \mathrm{Oct}$

8 LF Sep

12 LF Sep

16 RF Jul

16 RF Aug

16 RH Aug

1 LH Oct

19 RH Apr

3 LF Mar

4 LH Oct

8 LF May

11 RH Aug

19 RF Feb

1 RF Apr

1 RF Jul

1 RF Oct

1 RH Jun

1 RH Aug

1 RH Oct

1 LH Jan

1 LH Jun

2 LF Jun

$3 \mathrm{RH}$ Apr

3 RH May

3 LH Apr

3 LH May

4 LH Jan

4 LH Mar

4 LH Apr

4 LH May
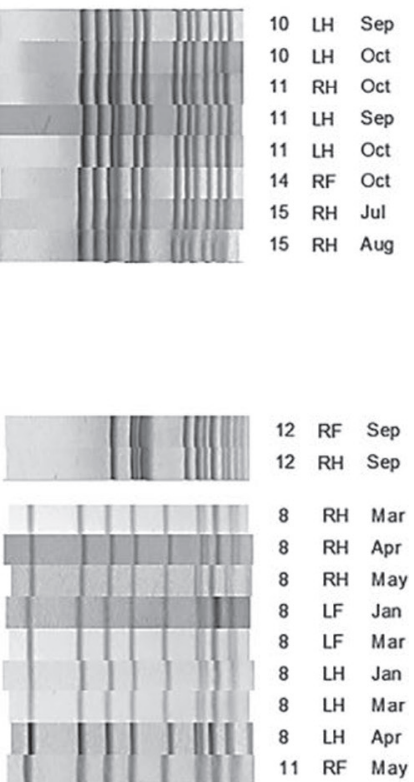

11 RF Jul

11 RF Oct
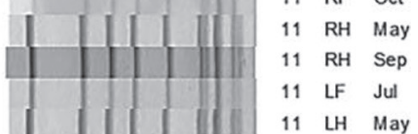

11 LH May

12 LF Jan

$12 \mathrm{LF} F \mathrm{Feb}$

12 LF Mar

15 RF Jul
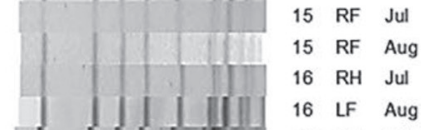

4 LH Jul

4 LH Aug

5 LF Jan

$6 \mathrm{RH} \mathrm{Jul}$

7 LF Jan

7 LF Apr

8 RF Jan

8 RF Apr

1 LF Jul

1 LF Jul

1 LF Ott

3 LF Apr

4 RF Jan

4 RF Apr

4 RF Aug

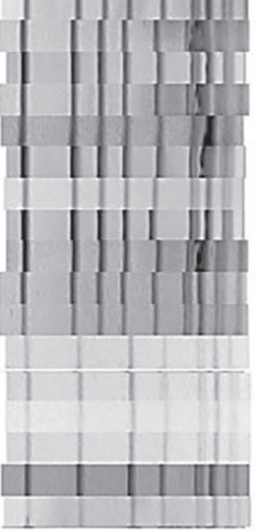

$\begin{array}{lll}17 & \text { LF } & \text { Feb } \\ 17 & \text { LH } & \text { Apr }\end{array}$

18 RF Mar

18 LF Jan

18 LF Apr

19 LF Mar

9 LF Apr

18 RF Apr

15 LH Aug

16 LF Jul

4 RF Oct

5 LF Feb

9 RF Sep

9 LF Oct

11 LF Sep

11 LF Oct

Figure 2. Dendrogram of the 11 pulsed-field gel electrophoresis (PFGE) type-subtype patterns of SmaI-digested DNA from 112 Streptococcus uberis isolates. The PFGE patterns on all selected $S$. uberis isolates are coded by cow, quarter, and month of collection. $\mathrm{RF}=\mathrm{right}$ front; $\mathrm{LF}=$ left front; $\mathrm{RH}=$ right hind; $\mathrm{LH}=$ left hind. 


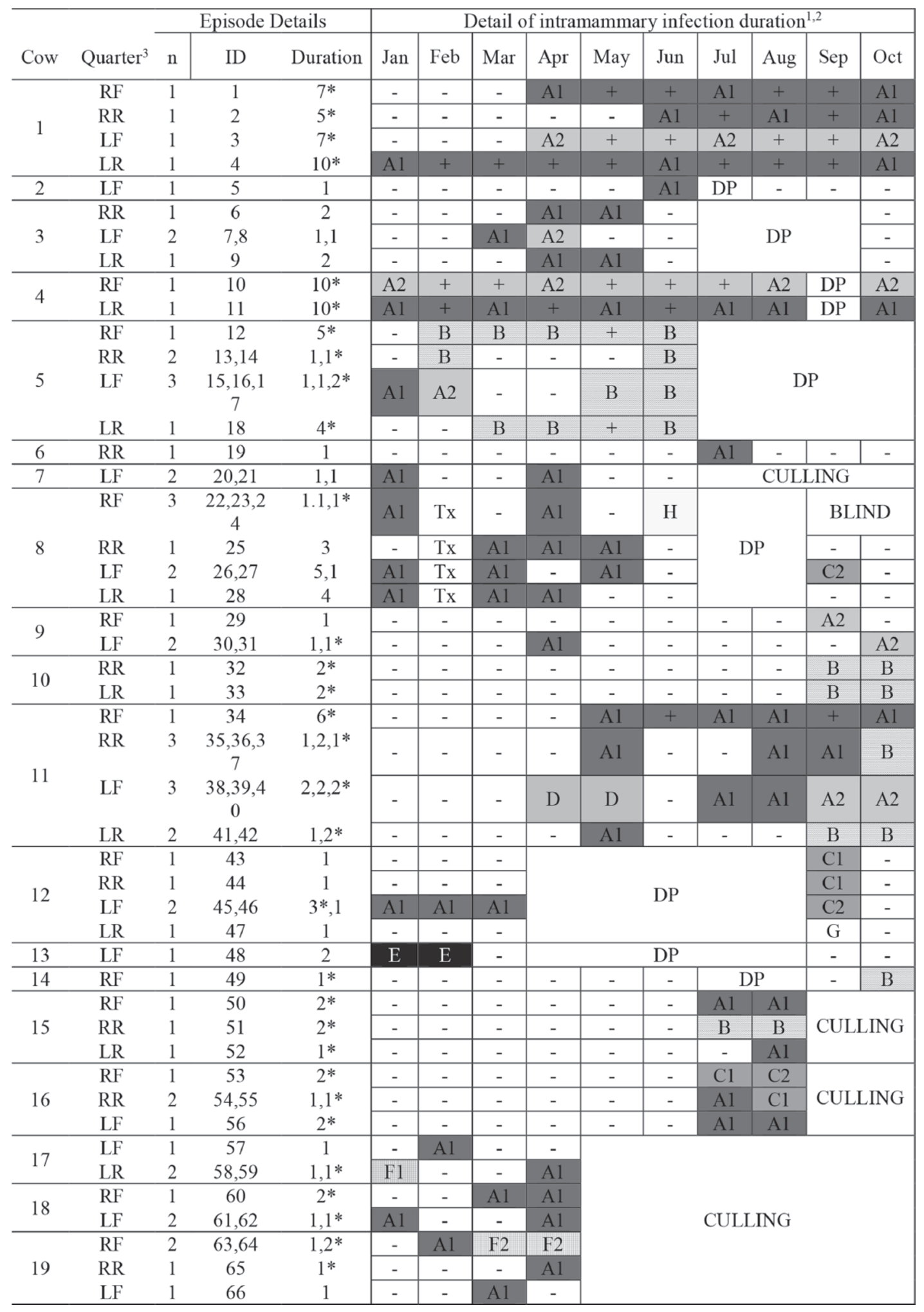

Figure 3. Episodes of intramammary infection in association with cow, quarter, and month of sampling determined by pulsed-field gel electrophoresis (PFGE) type-subtypes patterns. Duration of intramammary infection of each episode. — = quarter samples without Streptococcus uberis; blank $=$ no sampling period; $\mathrm{DP}=$ drying-off period; $\mathrm{Tx}=$ antibiotic treatment due to clinical mastitis. Shading of different cells and letters indicates subtype PFGE strains: A1 (dark gray); A2, B, D, F1, F2 (light gray); C1, C2 (gray); E (black); and G, H (white) of each episode, and + assuming the same strain as the nearest letter. RF, RR, LF, and LR = right front, right rear, left front, and left rear quarter, respectively. ${ }^{*}$ Censor episode. 
Table 1. Number and duration of infection, with SE, of IMI episodes per Streptococcus uberis pulsed-field gel electrophoresis (PFGE) type and subtype

\begin{tabular}{|c|c|c|c|c|c|}
\hline \multirow[b]{2}{*}{ PFGE type (subtype) } & \multirow[b]{2}{*}{ Total } & \multicolumn{2}{|c|}{ Spontaneous cure } & \multicolumn{2}{|c|}{ Censored } \\
\hline & & No. $(\%)$ & Duration (mo) & No. $(\%)$ & Duration (mo) \\
\hline \multicolumn{6}{|l|}{ Contagious S. uberis ${ }^{1}$} \\
\hline $\mathrm{A}(\mathrm{A} 1, \mathrm{~A} 2)$ & 43 & $26(60.5)$ & $1.5 \pm 0.2^{\mathrm{a}}$ & $17(39.5)$ & $4.18 \pm 0.84^{\mathrm{b}}$ \\
\hline B & 11 & $1(9.1)$ & $1 \pm 0$ & $10(90.9)$ & $2.2 \pm 0.42$ \\
\hline $\mathrm{C}(\mathrm{C} 1, \mathrm{C} 2)$ & 6 & $4(66.6)$ & $1 \pm 0$ & $2(33.3)$ & $1.5 \pm 0.5$ \\
\hline \multicolumn{6}{|l|}{ Environmental S. uberis ${ }^{1}$} \\
\hline $\mathrm{D}, \mathrm{E}, \mathrm{F}(\mathrm{F} 1, \mathrm{~F} 2), \mathrm{G}, \mathrm{H}$ & 6 & $4(66.6)$ & $1.5+0.28$ & $2(33.3)$ & $1.5 \pm 0.5$ \\
\hline
\end{tabular}

${ }^{\mathrm{a}, \mathrm{b}}$ Different superscripts indicate a significant difference of durations between spontaneous cure and censored episode.

${ }^{1}$ Contagious $S$. uberis indicated by the episodes with at least a pair of the same PFGE type, and environmental S. uberis indicated by episodes with only one occurrence during the study.

Numbers of episodes and their duration of infection among S. uberis PFGE type/subtypes separated into those with and without spontaneous cures are shown in Table 1. Contagious $S$. uberis types were defined for PFGE type A, B, and C, and environmental S. uberis type was defined for PFGE type D, E, F, G, and H. For episodes with spontaneous cure, most PFGE types had a duration of infection of less than 2 mo. In contrast, for right-censored episodes, PFGE type A and B had an average duration of more than $2 \mathrm{mo}$, and less than 2 mo for PFGE type C.

A Kaplan-Meier analysis on time to spontaneous cures of $S$. uberis IMI among PFGE types is shown in Figure 4. Approximately $90 \%$ of $S$. uberis strain B were censored or without spontaneous cures and persisted until the end of the study, and there was only one episode with spontaneous cure after 1 mo. Median of the Kaplan-Meier curve indicated that 50\% of PFGE type A, C, and environmental S. uberis cured spontaneously at approximately 2, 1, and 2 mo, respectively. Based on the results from Cox's proportional hazard model, environmental $S$. uberis mastitis episodes were likely to have spontaneous cure with shorter infection duration than S. uberis with PFGE type B $(P=0.057$; hazard ratio $=8.4$ ). A Kaplan-Meier analysis on time to spontaneous cure of $S$. uberis IMI with PFGE type A comparing episodes that started in early and late lactation is shown in Figure 5. Most PFGE type A episodes starting in early lactation did not achieve spontaneous cure. In contrast, most of the IMI with type A starting in late lactation did achieve spontaneous cures. This difference in time to spontaneous cure was statistically significant $(P<0.05$; hazard ratio $=7.57)$.

\section{DISCUSSION}

A longitudinal study was undertaken to determine the molecular epidemiology of S. uberis IMI in a single dairy herd. Before the longitudinal study, the herd took part in a mastitis investigation and S. uberis was found to be the dominant pathogen. Due to the continuing poor milk quality management in this farm, high rates of new IMI and persistent IMI, and low spontaneous cure resulted in continuous dominance of $S$. uberis infections.

Various methods have been developed to differentiate $S$. uberis strains. In the present study the PFGE method was used to investigate the epidemiology of $S$. uberis mastitis. The use of PFGE was verified to be a highly discriminatory method for detecting differences in strains of S. uberis (Gillespie and Oliver, 2004). Also, PFGE is a technique of choice for typing bacterial isolates in short-term or local epidemiological contexts (Shome et al., 2012). The method is known to identify rapidly evolving genetic changes and identify changes in the S. uberis genome ( $\mathrm{Li}$ et al., 2009).

\section{Transmission Dynamic of S. uberis IMI}

The $S$. uberis isolates collected in this study showed a limited number of PFGE types, 11 strains from 112 isolates (Figure 2). This is in agreement with results from Zadoks et al. (2003) who found 12 strains among 111 isolates and 7 strains among 41 isolates in 2 herds by using random amplified polymorphic DNA fingerprint. In contrast to this study, several studies have reported a high degree of heterogeneity among isolates, suggesting that the identified cases of S. uberis are not clonal and are more likely to arise from the cows' environment (Khan et al., 2004; McDougall et al., 2004; Abureema et al., 2014). Genetic variability has been reported to be high among $E$. coli isolates, a known environmental mastitis pathogen. Most of the E. coli strains were not genetically related as shown by PFGE (Moser et al., 2013; Silva et al., 2013).

In the current study we observed that in addition to the limited number of PFGE types, a predominance of PFGE type A1 was identified. New IMI episodes 


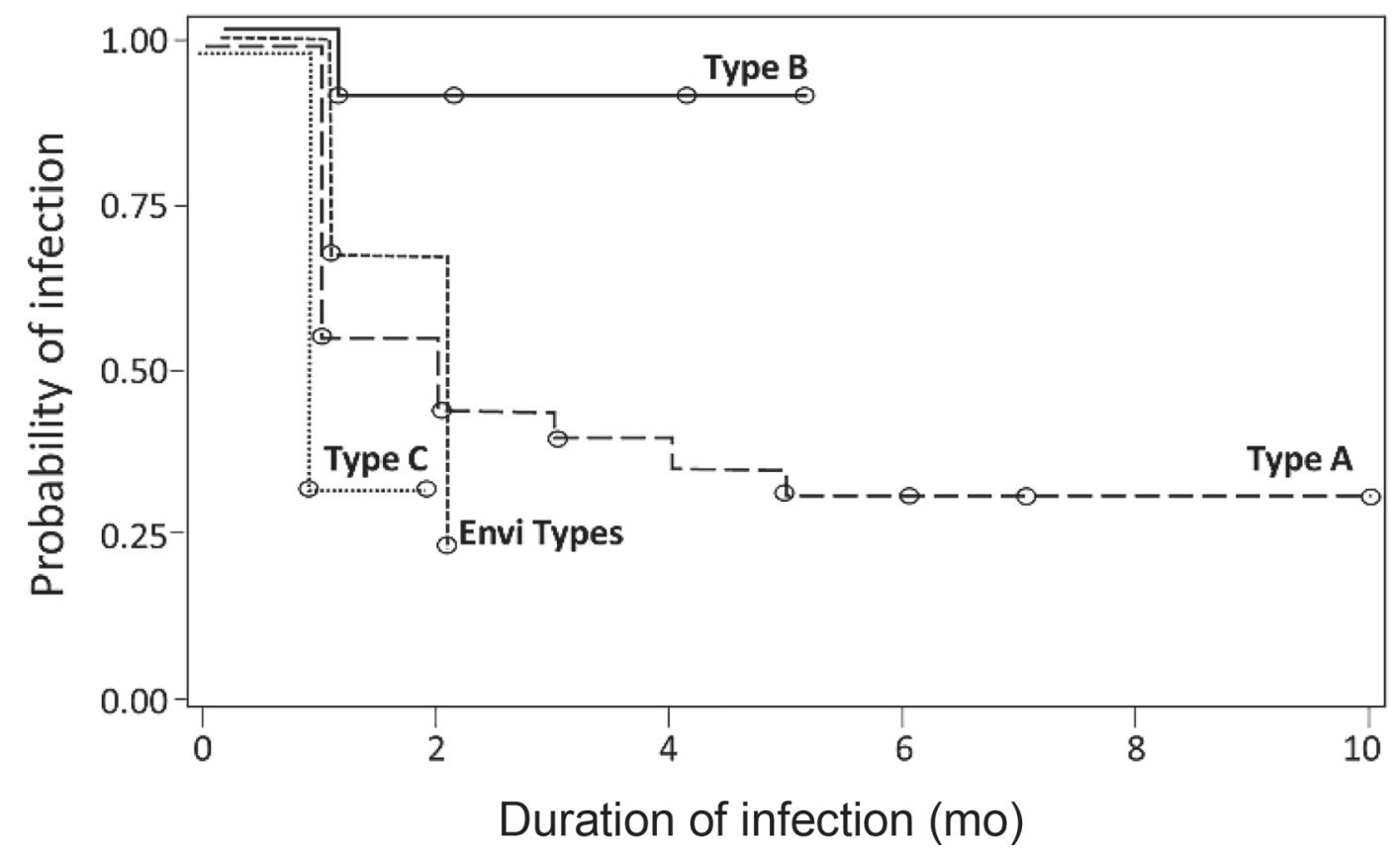

Figure 4. Kaplan-Meier curve of Streptococcus uberis IMI separated based on pulsed-field gel electrophoresis types A (A1 and A2), B, C (C1 and C2), and all environmental S. uberis (Envi).

were mostly caused by existing PFGE types in the herd. The finding of identical PFGE type in different quarters of the same cow and in different cows within the herd suggest that either contagious spread of $S$. uberis between quarters and cow or from a common environmental source within the farm may be occurring (Phuektes et al., 2001; Rato et al., 2009; Shome et al., 2012; Aburrema et al., 2014). We suggest that contagious transmission is the more likely cause of the clonal infection pattern in this herd. The cows in the tiestalls on this farm are less likely to share a common environmental source and the poor milking practices in this farm would facilitate cow-to-cow transmission. This farm did not use individual paper towels, immediate post-milking teat disinfection, segregating infected cows and milking known infected cows last, blanket dry cow therapy, or routine culling of cows with chronic or recurrent mastitis. Such management would certainly facilitate cow-to-cow transmission of prevalent S. uberis strains. Direct transmission from an infected quarter to uninfected quarters would likely occur during the milking process.

Occurrence of a limited number of strains in a herd is generally associated with a contagious pathogen such as Streptococcus agalactiae and Staphylococcus aureus (Lam et al., 1996; Baseggio et al., 1997; Wang et al., 1999). Our results suggest that contagious transmission may also occur in the case of S. uberis IMI. However, direct contact with a common environmental source can- not be discounted. In our results, PFGE type/subtype $\mathrm{B}, \mathrm{C} 1$, and $\mathrm{C} 2$ were not isolated in the first sampling, indicating that these strains may be coming from environmental reservoirs. These strains were also found in different quarters of the same cow and in different cows within the herd. In previous studies, when comparing the distribution of strains between environmental, fecal, and milk isolates, a wide variety of $S$. uberis strains was shown to be present in these multiple sample types (Zadoks et al., 2005; Lopez-Benavides et al., 2007). In these and other studies, a high level of heterogeneity among PFGE patterns within herds was observed (Phuektes et al., 2001; Zadoks et al., 2001; McDougall et al., 2004), indicating an environmental source of $S$. uberis. In addition, some strains from isolates collected from the environment were also identified from cows with an IMI or clinical mastitis (Lopez-Benavides et al., 2007). These observations may help explain cowto-environment or environment-to-cow transmission, and the presence of a single strain in multiple quarters or cows in a herd may be due to exposure to a strain that is also predominant in the environment (Zadoks et al., 2011). Nevertheless, within-cow or between-cow transmission of PFGE types may occur as is most likely the case in the clonal occurrence of $S$. uberis in the herd reported in our study. In studies of $E$. coli IMI, it was shown that repeated clinical cases occurring within a quarter or in different quarters of the same animal were caused by the same strain as the initial case, sug- 


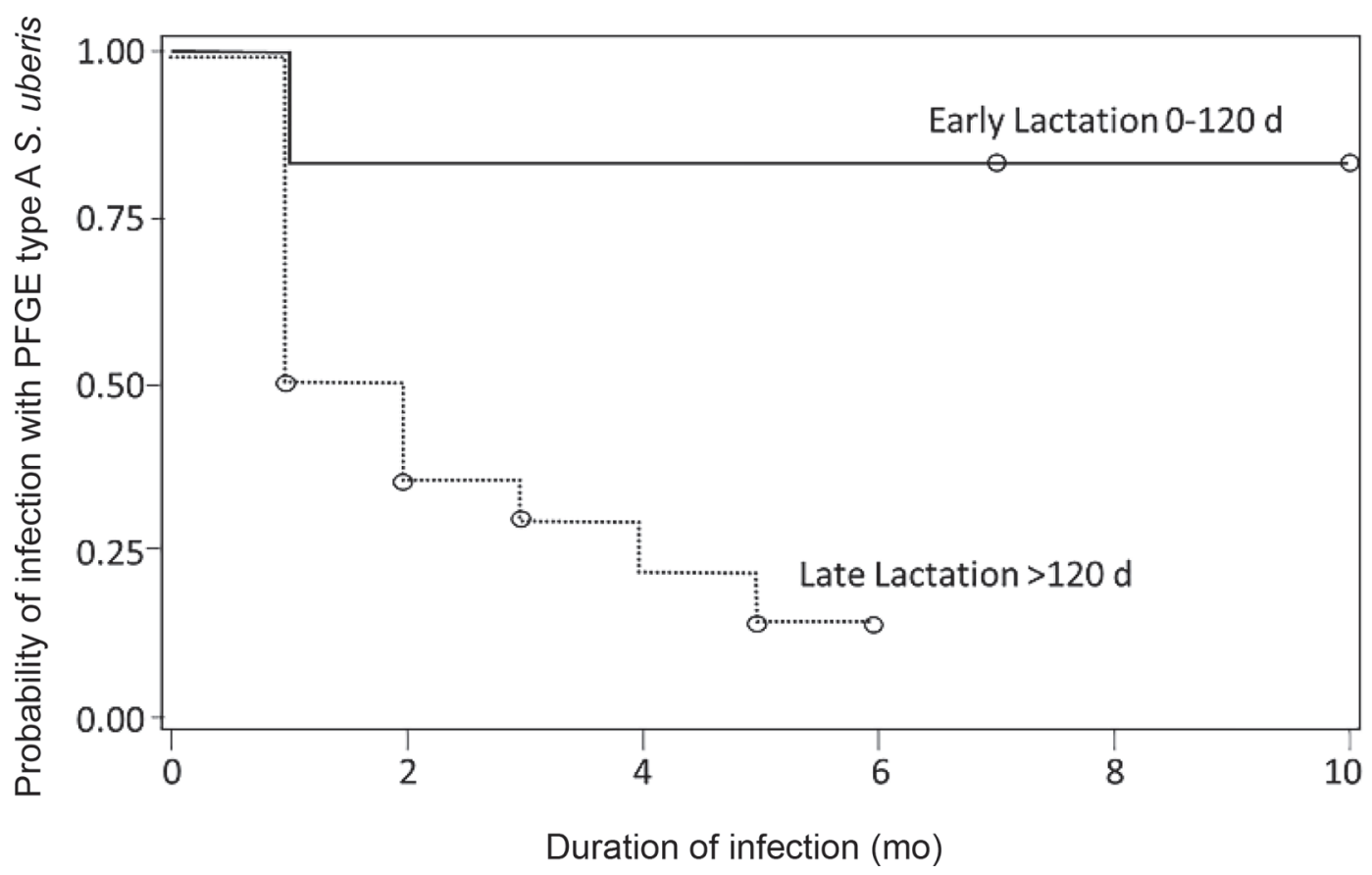

Figure 5. Kaplan-Meier curve for Streptococcus uberis IMI in pulsed-field gel electrophoresis (PFGE) group A separated based on period of lactation at the starting point in lactation of the IMI (early, $n=6$; late, $n=3$ ).

gesting the occurrence of within-cow transmission of this pathogen (Döpfer et al., 1999; Bradley and Green, 2001).

In a quarter with a new IMI, the infection may be subsequently cleared as the result of an adequate immune response. Based on the observations in the study, we propose that this recent cure does not protect the quarter against being re-infected by the same or a different strain of the same bacterial species. The repeated episodes of infection were due to reinfection with the original PFGE type or infection with a different PFGE type of $S$. uberis, as shown in cow $5,7,8,9,11,12$, 17 , and 18. Such recurrent episodes of $S$. uberis infection due to re-infection with the original strain have been suggested by previous studies using other typing methods. For example, Zadoks et al. (2003) found that 35 of 40 long duration episodes of infection were due to persistent infection with the same random amplified polymorphic DNA type. Pullinger et al. (2007) found that 24 of 33 of persistent infections were due to re-infection with the same sequence type. In contrast, Abureema et al. (2014) reported that the majority of recurrences of clinical mastitis (20 of 27) were caused by re-infection with a new strain of $S$. uberis, whereas a small number of recurrences ( 5 of 27 ) were caused by the initial strain. Our results showed that 5 of 13 showed a re-infection with the same PFGE type and 8 of 13 showed a re-infection with a different PFGE type.

\section{Transient or Persistent Episodes of S. uberis}

The duration of infection in the present study will be underestimated because some quarters were already infected at the start of the study (left censored) and some remained infected at the end of study or end of infection due to drying off, culling, or antibiotic treatment (right censored). In our results, most IMI, regardless of censored episodes, were relatively short, or transient, as shown in Figure 3 and Table 1. This is consistent with a previous study (McDougall et al., 2004). Except for PFGE type B, all PFGE types of S. uberis showed a spontaneous cure of $50 \%$ within 2 mo of IMI (Figure 4). Zadoks et al. (2003) pointed out that duration of infection was significantly associated with specific $S$. uberis strains, in which the predominant strain had longer duration. The PFGE type/subtype D, E, F1, F2, H, and $\mathrm{G}$, determined as environmental $S$. uberis episodes, caused only transient episodes of infection, suggesting that they could not be transmitted to another quarter and could not persist in the udder. However, PFGE types $\mathrm{F} 2$ and $\mathrm{H}$ defined as censored episodes might not prove to be environmental pathogens if the observational period was prolonged. In contrast, PFGE type B episodes had a lower proportion of spontaneous cure $(9.1 \%)$ as shown in Figure 5. Although the average duration of infection from all cases was short at $2.2 \pm$ 0.42 mo (Table 1 ). The low spontaneous cure in type B 
(cure of 10\%) was possibly due to an increased intracellular survival ability of this S. uberis strain. This ability of $S$. uberis to adhere to and to invade mammary epithelium cells has been suggested in previous studies (Thomas et al., 1994; Matthews et al., 1994; Almeida et al., 1996). The ability of S. uberis to survive intracellularly would explain persistent infections, and intracellular survival would also protect the bacteria from the defense mechanisms of the mammary gland and from antimicrobial action. Clearly, persistent infections are important because they could play a major role as the source of infection in a herd (Phuektes et al., 2001).

In contrast to other strains, S. uberis with PFGE type A showed both transient and persistent IMI with a wide range of duration of infection from 1 mo to at least 10 mo (as right-censored episodes). Quarters infected with $S$. uberis PFGE type A and spontaneous cure had a shorter duration of infection than those without spontaneous cure (Table 1 ). In addition, quarters with IMI episodes of $S$. uberis type A occurring during early lactation had longer duration of infection than those where the IMI occurred in late lactation (Figure 2). This finding is supported by previous studies where persistence of infection with a specific strain of $S$. uberis was considered to be more likely due to cow factors rather than strain factors (McDougall et al., 2004; Pullinger et al., 2007; Abureema et al., 2014). In early lactation, many cows will have a negative energy balance and subsequently suffer from hyperketonemia (Suriyasathaporn et al., 2000a). The persistent IMI from $S$. uberis with PFGE type A during early lactation might be related to impairment of udder defense mechanisms during early lactation, possibly related to hyperketonemia (Suriyasathaporn et al., 2000a). These results on the epidemiology of $S$. uberis IMI are important information for the implementation of targeted mastitis control programs in a herd. Further investigation is required to clarify the relative importance of particular strains and virulence factors in clinical and epidemiological characteristics of persistent S. uberis infection in dairy herds. Moreover, the host characteristics of $S$. uberis strains that are related to persistent infection should be determined.

In conclusion, most IMI episodes of $S$. uberis were short with spontaneous cure. The limited number of PFGE types (11), a few predominant PFGE types $(3 / 11)$, and the finding of identical PFGE type in different quarters of the same cow and in different cows within a herd suggest that a contagious route of transmission played a role in in this herd. At least 3 types of contagious IMI S. uberis can be defined as (1) short duration of infection and likely to have spontaneous cure (an example would be PFGE type C), (2) long duration of infection and no or little spontaneous cure (an example is PFGE type B), and (3) wide range of duration of infection and spontaneous cure possible depending on host defense capacity (an example is PFGE type $\mathrm{A}$ in this study).

\section{ACKNOWLEDGMENTS}

This research was supported by the Royal Golden Jubilee Ph.D. Program - The Thailand Research Fund (Bangkok, Thailand). The authors thank Wantanwa Mongkol, Tanittian Panyamongkol, and the owner of a dairy herd from Phatung dairy co-operatives, Chiang Mai province, Thailand, for their participation and cooperation. We are grateful to Sukolrat Boonyayatra for guidance and laboratory support in PFGE technique. We gratefully acknowledge Prapas Patchanee (Integrative Research Center for Veterinary Preventive Medicine, Faculty of Veterinary Medicine, Chiang Mai University, Chiang Mai, Thailand) for assistance with BioNumerics v. 7.0 software analysis. The authors declare that they have no conflict of interest.

\section{REFERENCES}

Abureema, S., P. Smooker, J. Malmo, and M. Deighton. 2014. Molecular epidemiology of recurrent clinical mastitis due to Streptococcus uberis: Evidence of both an environmental source and recurring infection with the same strain. J. Dairy Sci. 97:285-290. https:// doi.org/10.3168/jds.2013-7074.

Almeida, R. A., D. A. Luther, S. J. Kumar, L. F. Calvinho, M. S. Bronze, and S. P. Oliver. 1996. Adherence of Streptococcus uberis to bovine mammary epithelial cells and to extracellular matrix proteins. Zentralbl. Veterinarmed. B 43:385-392. https://doi.org/ 10.1111/j.1439-0450.1996.tb00330.x.

Baseggio, N., P. D. Mansell, J. W. Browning, and G. F. Browning. 1997. Strain differentiation of isolates of streptococci from bovine mastitis by pulsed-field gel electrophoresis. Mol. Cell. Probes 11:349-354. https://doi.org/10.1006/mcpr.1997.0126.

Bradley, A. J., and M. J. Green. 2001. Adaptation of Escherichia coli to the bovine mammary gland. J. Clin. Microbiol. 39:1845-1849. https://doi.org/10.1128/JCM.39.5.1845-1849.2001.

Döpfer, D., H. W. Barkema, T. J. G. M. Lam, Y. H. Schukken, and W. Gaastra. 1999. Recurrent clinical mastitis caused by Escherichia coli in dairy cows. J. Dairy Sci. 82:80-85. https://doi.org/10.3168/ jds.S0022-0302(99)75211-2.

Ezzat Alnakip, M., M. Quintela-Baluja, K. Böhme, I. Fernández-No, S. Caamaño-Antelo, P. Calo-Mata, and J. Barros-Velázquez. 2014. The immunology of mammary gland of dairy ruminants between healthy and inflammatory conditions. J. Vet. Med. 2014:659801. https://doi.org/10.1155/2014/659801.

Gillespie, B. E., and S. P. Oliver. 2004. Comparison of an automated ribotyping system, pulsed-field gel electrophoresis and randomly amplified polymorphic DNA fingerprinting for differentiation of Streptococcus uberis strains. Biotechnology 3:165-172. https://doi .org/10.3923/biotech.2004.165.172.

Harmon, R. J., R. J. Eberhart, D. E. Jasper, B. E. Langlois, and R. Wilson. 1990. Microbiological Procedures for the Diagnosis of Bovine Udder Infection, 3rd ed. National Mastitis Council. Inc., Arlington, VA.

Hassan, A. A., I. U. Khan, A. Abdulmawjood, and C. Lämmler. 2001. Evaluation of PCR methods for rapid identification and differentiation of Streptococcus uberis and Streptococcus parauberis. J. Clin. Microbiol. 39:1618-1621. https://doi.org/10.1128/JCM.39.4 .1618-1621.2001. 
Khan, I. U., A. Hassan, A. Abdulmawjood, C. Lämmler, W. Wolter, and M. Zschöck. 2003. Identification and epidemiological characterization of Streptococcus uberis isolated from bovine mastitis using conventional and molecular methods. J. Vet. Sci. 4:213-224. https://doi.org/10.4142/jvs.2003.4.3.213.

Lam, T. J. G. M., L. J. A. Lipman, Y. H. Schukken, W. Gaastra, and A. Brand. 1996. Epidemiological characteristics of bovine clinical mastitis caused by Staphylococcus aureus and Escherichia coli studied by DNA fingerprinting. Am. J. Vet. Res. 57:39-42.

Leelahapongsathon, K., Y. H. Schukken, T. Pinyopummintr, and W. Suriyasathaporn. 2016. Comparison of transmission dynamics between Streptococcus uberis and Streptococcus agalactiae intramammary infections. J. Dairy Sci. 99:1418-1426. https://doi.org/10 $.3168 /$ jds.2015-9950.

Li, W., D. Raoult, and P. E. Fournier. 2009. Bacterial strain typing in the genomic era. FEMS Microbiol. Rev. 33:892-916. https://doi .org/10.1111/j.1574-6976.2009.00182.x.

Lopez-Benavides, M. G., J. H. Williamson, G. D. Pullinger, S. J. LacyHulbert, R. T. Cursons, and J. A. Leigh. 2007. Field observations on the variation of Streptococcus uberis populations in a pasturebased dairy farm. J. Dairy Sci. 90:5558-5566. https://doi.org/10 .3168/jds.2007-0194.

Matthews, K. R., R. A. Almeida, and S. P. Oliver. 1994. Bovine mammary epithelial cell invasion by Streptococcus uberis. Infect. Immun. 62:5641-5646.

McDougall, S., T. J. Parkinson, M. Leyland, F. M. Anniss, and S. G. Fenwick. 2004. Duration of infection and strain variation in Streptococcus uberis isolated from cows' milk. J. Dairy Sci. 87:20622072. https://doi.org/10.3168/jds.S0022-0302(04)70024-7.

Moser, A., R. Stephan, S. Corti, and A. Lehner. 2013. Resistance profiles and genetic diversity of Escherichia coli strains isolated from acute bovine mastitis. Schweiz. Arch. Tierheilkd. 155:351-357. https://doi.org/10.1024/0036-7281/a000470.

Phuektes, P., P. Mansell, R. S. Dyson, N. D. Hooper, J. S. Dick, and G. F. Browning. 2001. Molecular epidemiology of Streptococcus uberis isolates from dairy cows with mastitis. J. Clin. Microbiol. 39:1460-1466. https://doi.org/10.1128/JCM.39.4.1460-1466.2001.

Pullinger, G. D., T. J. Coffey, M. C. Maiden, and J. A. Leigh. 2007. Multilocus-sequence typing analysis reveals similar populations of Streptococcus uberis are responsible for bovine intramammary infections of short and long duration. Vet. Microbiol. 119:194-204. https://doi.org/10.1016/j.vetmic.2006.08.015.

Rato, M. G., R. Bexiga, F. Nunes, L. M. Cavaco, C. L. Vilela, and I. Santos-Sanches. 2008. Molecular epidemiology and population structure of bovine Streptococcus uberis. J. Dairy Sci. 91:45424551. https://doi.org/10.3168/jds.2007-0907.

Shome, B. R., M. Bhuvana, S. D. Mitra, N. Krithiga, R. Shome, D. Velu, A. Banerjee, S. Barbuddhe, K. Prabhudas, and H. Rahman. 2012. Molecular characterization of Streptococcus agalactiae and Streptococcus uberis isolates from bovine milk. Trop. Anim. Health Prod. 44:1981-1992. https://doi.org/10.1007/s11250-012-0167-4.

Silva, V. O., I. F. Espeschit, and M. A. S. Moreira. 2013. Clonal relationship of Escherichia coli biofilm producer isolates obtained from mastitic milk. Can. J. Microbiol. 59:291-293. https://doi.org/10 $.1139 /$ cjm-2013-0053.

Supré, K., F. Haesebrouck, R. N. Zadoks, M. Vaneechoutte, S. Piepers, and S. De Vliegher. 2011. Some coagulase-negative Staphylococ- cus species affect udder health more than others. J. Dairy Sci. 94:2329-2340. https://doi.org/10.3168/jds.2010-3741.

Suriyasathaporn, W., C. Heuer, E. N. Noordhuizen-Stassen, and Y. H. Schukken. 2000a. Hyperketonemia and the impairment of udder defense: A review. J. Vet. Res. (Pulawy) 31:397-412. https://doi .org/10.1051/vetres:2000128.

Suriyasathaporn, W., Y. H. Schukken, M. Nielen, and A. Brand. 2000b. Low somatic cell count: A risk factor for subsequent clinical mastitis in a dairy herd. J. Dairy Sci. 83:1248-1255. https:// doi.org/10.3168/jds.S0022-0302(00)74991-5.

Tenover, F. C., R. D. Arbeit, R. V. Goering, P. A. Mickelsen, B. E. Murray, D. H. Persing, and B. Swaminathan. 1995. Interpreting chromosomal DNA restriction patterns produced by pulsed-field gel electrophoresis: Criteria for bacterial strain typing. J. Clin. Microbiol. 33:2233-2239.

Thomas, L. H., W. Haider, A. W. Hill, and R. S. Cook. 1994. Pathologic findings of experimentally induced Streptococcus uberis infection in the mammary gland of cows. Am. J. Vet. Res. 55:1723-1728.

Thompson-Crispi, K., H. Atalla, F. Miglior, and B. A. Mallard. 2014. Bovine mastitis: Frontiers in immunogenetics. Front. Immunol. 5:493. https://doi.org/10.3389/fimmu.2014.00493.

Todhunter, D. A., K. L. Smith, and J. S. Hogan. 1995. Environmental streptococcal intramammary infections of the bovine mammary gland. J. Dairy Sci. 78:2366-2374. https://doi.org/10.3168/jds .S0022-0302(95)76864-3.

Wang, S. M., M. A. Deighton, J. A. Capstick, and N. Gerraty. 1999 Epidemiological typing of bovine streptococci by pulsed-field gel electrophoresis. Epidemiol. Infect. 123:317-324. https://doi.org/10 $.1017 /$ S0950268899002745.

Zadoks, R. N., H. G. Allore, H. W. Barkema, O. C. Sampimon, Y. T. Gröhn, and Y. H. Schukken. 2001. Analysis of an outbreak of Streptococcus uberis mastitis. J. Dairy Sci. 84:590-599. https://doi .org/10.3168/jds.S0022-0302(01)74512-2.

Zadoks, R. N., B. E. Gillespie, H. W. Barkema, O. C. Sampimon, S. P. Oliver, and Y. H. Schukken. 2003. Clinical, epidemiological and molecular characteristics of Streptococcus uberis infections in dairy herds. Epidemiol. Infect. 130:335-349. https://doi.org/10.1017/ S0950268802008221.

Zadoks, R. N., J. R. Middleton, S. McDougall, J. Katholm, and Y. H. Schukken. 2011. Molecular epidemiology of mastitis pathogens of dairy cattle and comparative relevance to humans. J. Mammary Gland Biol. Neoplasia 16:357-372. https://doi.org/10.1007/s10911 $-011-9236-\mathrm{y}$.

Zadoks, R. N., L. L. Tikofsky, and K. J. Boor. 2005. Ribotyping of Streptococcus uberis from a dairy's environment, bovine feces and milk. Vet. Microbiol. 109:257-265. https://doi.org/10.1016/ j.vetmic.2005.05.008

\section{ORCIDS}

K. Leelahapongsathon @ https://orcid.org/0000-0001-6101-5191

Y. H. Schukken ( https://orcid.org/0000-0002-8250-4194

A. Srithanasuwan () https://orcid.org/0000-0003-2837-7187

W. Suriyasathaporn ํㅡ https://orcid.org/0000-0002-2327-195X 